\title{
Sensitivity of climate response to variations in freshwater hosing location
}

\author{
Thomas Kleinen • Timothy J. Osborn • Keith R. Briffa
}

Received: 23 September 2008 / Accepted: 4 March 2009 / Published online: 27 March 2009

(C) Springer-Verlag 2009

\begin{abstract}
In a recent intercomparison of the response of general circulation models (GCMs) to highlatitude freshwater forcing (Stouffer et al., J Climate 19(8):1365-1387, 2006), a number of the GCMs investigated showed a localised warming response in the high-latitude North Atlantic, as opposed to the cooling that the other models showed. We investigated the causes for this warming by testing the sensitivity of the meridional overturning circulation (MOC) to variations in freshwater forcing location, and then analysing in detail the causes of the warming. By analysing results from experiments with HadCM3, we are able to show that the high-latitude warming is independent of the exact location of the additional freshwater in the North Atlantic or Arctic Ocean basin. Instead, the addition of freshwater changes the circulation in the sub-polar gyre, which leads to enhanced advection of warm, saline, sub-surface water into the Greenland-IcelandNorwegian Sea despite the overall slowdown of the MOC. This sub-surface water is brought to the surface by convection, where it leads to a strong warming of the surface waters and the overlying atmosphere.
\end{abstract}

Responsible Editor: Richard John Greatbatch

T. Kleinen $(\bowtie) \cdot$ T. J. Osborn · K. R. Briffa

Climatic Research Unit, School of Environmental Sciences,

University of East Anglia, Norwich, NR4 7TJ, UK

e-mail: thomas.kleinen@zmaw.de

Present Address:

T. Kleinen

Max Planck Institute for Meteorology, Bundesstraße 53,

20146 Hamburg, Germany
Keywords Thermohaline circulation • Meridional overturning circulation $\cdot$ Freshwater hosing $\cdot$ Sub-polar gyre

\section{Introduction}

The meridional overturning circulation (MOC), closely linked with the thermohaline circulation, in the North Atlantic is important for the Northern Hemisphere, and especially European, climate. This is on the one hand due to the large northward heat transport by the MOC (Ganachaud and Wunsch 2000), and on the other hand due to its nonlinear behaviour and, therefore, the possibility of abrupt change (Manabe and Stouffer 1995; Rahmstorf 1995; Stocker and Schmittner 1997).

Briefly, the North Atlantic MOC can be summarised as warm, salty surface waters flowing northwards in the Atlantic as part of the Gulf Stream and the North Atlantic current. In the high northern latitudes of the Atlantic, these waters then cool by exchanging heat with the overlying atmosphere. Once the density has increased sufficiently due to the cooling, convection sets in, and cold dense deep water is formed. In the North Atlantic, deep water formation mainly occurs in two locations: in the Greenland-Iceland-Norwegian (GIN) sea and in the Labrador Sea.

At depth, the GIN sea is isolated from the rest of the Atlantic ocean by the Greenland-Scotland ridge (GSR). The deep water overflows the ridge through channels, with the Denmark Strait west of Iceland and the Faroe Bank Channel east of Iceland as the most important (Hansen and Østerhus 2000). South of the ridges, the overflow water then mixes with ambient water, thus forming the North Atlantic deep water 
(NADW). The NADW then passes around the southern tip of Greenland and through the Labrador sea as the deep western boundary current (DWBC). In the Labrador Sea, additional deep water, the Labrador Sea water, is formed through deep convection (Cuny et al. 2005), which mixes with the DWBC (Lavender et al. 2000). Past the Labrador Sea, the DWBC continues southward along the western boundary of the Atlantic basin at a depth of approximately 2,500 $\mathrm{m}$. It traverses the entire Atlantic Ocean and is finally mixed into other water masses in the Southern Ocean (Warren 1981).

The overall current system is assumed to be driven by the meridional pressure gradient between the deep water formation areas and the South Atlantic (Rahmstorf 1996), with a linear relation shown in HadCM3 (Thorpe et al. 2001), as well as MOM (Rahmstorf 1996), while other authors propose a onethird power relationship (Park 1999). The picture of the MOC that emerges from box models, e.g. Stommel (1961), Rooth (1982), Rahmstorf (1996) and Scott et al. (1999), is one of a nonlinear circulation system that can collapse in a bifurcation, once a density threshold is crossed (Rahmstorf 1995). The system is, therefore, rather sensitive to temperature and salinity perturbations in the Nordic Seas (Rahmstorf 1995; Mikolajewicz and Voss 2000), and it is presently feared that a disruption of the system might take place due to global warming (Jansen et al. 2007).

So-called "freshwater hosing experiments", i.e. experiments where the North Atlantic freshwater balance is perturbed by artificially adding freshwater to the ocean basin, have generated substantial interest in recent years. Perturbations in the MOC have been investigated as causes for Younger Dryas cooling, e.g. Manabe and Stouffer (1997), Tarasov and Peltier (2005) and Peltier et al. (2006), and the 8.2-kiloyear event (Renssen et al. 2001; Wiersma et al. 2006; Wiersma and Renssen 2006). Furthermore, the response of the MOC to future warming due to the anthropogenic greenhouse effect has been investigated, e.g. Manabe and Stouffer $(1988,1995)$, Rahmstorf and Ganopolski (1999), Wood et al. (1999), Thorpe et al. (2001) and Vellinga and Wood (2008). Here, one focus has been on increased runoff from a melting Greenland ice sheet (Fichefet et al. 2003; Jungclaus et al. 2006; Driesschaert et al. 2007).

While a recent intercomparison of the MOC response to increasing greenhouse gas concentrations in different climate models found that the system responds with a gradual slowing of the MOC in all models investigated (Gregory et al. 2005), at least one other study gives a higher probability for a collapse of the MOC (Challenor et al. 2006). In a recent intercompar- ison of freshwater hosing experiments, Stouffer et al. (2006) found that these freshwater perturbations, contrary to expectations, did not lead to the ubiquitous cooling in the North Atlantic basin that might be expected. Instead, it led to a warming in some areas of the North Atlantic for some of the climate models taking part in the intercomparison. Stouffer et al. (2006) speculate that this rather unexpected result might be due to the experimental design, where freshwater was added in a band of $50^{\circ}-70^{\circ} \mathrm{N}$ in the North Atlantic basin, since the warming occurred just north of the area where freshwater was added. Saenko et al. (2007) report a similar warming centred around the Labrador Sea region in experiments where freshwater is added right at the continental boundary of either Greenland or the Labrador sea. In their case, the warming appears in a different location, though, and the mechanism they report, a retreat of sea ice in the sub-polar Atlantic, induced through changes in wind stress curl, does not occur in the experiments reported here.

The aim of the current paper is to investigate the sensitivity of the climatic response to variations in the experimental design employed by Stouffer et al. (2006) and to explore the physical and dynamical reasons for this unexpected warming using the coupled general circulation model HadCM3. Since resolution in HadCM3 is comparatively coarse, results from such experiments may not reflect what would happen on small scales in the "real" climate system. Nonetheless, we can aim to understand the cause of unexpected model results (as those reported by Stouffer et al. (2006)), while keeping in mind that the real climate system might react differently.

The layout of this paper is as follows: In Section 2, we describe the model used, as well as the experimental design. In Section 3, we show results for various highlatitude locations of freshwater forcing, while Section 4 is devoted to the analysis of the reasons for the highlatitude warming. Finally, we conclude this paper with a summary and discussion in Section 5.

\section{Model experiments}

In order to investigate the sensitivity of the climatic response to freshwater hosing of the North Atlantic, we performed a number of experiments with the third version of the Hadley Centre coupled ocean-atmosphere model HadCM3 (Pope et al. 2000; Gordon et al. 2000; Collins et al. 2001). The atmospheric component of $\mathrm{HadCM} 3$ uses a $3.75^{\circ}$ by $2.5^{\circ}$ longitude-latitude grid with 19 levels in the vertical, while the ocean has a resolution of $1.25^{\circ}$ by 
$1.25^{\circ}$, and 20 unevenly spaced layers in the vertical. The model produces a stable climate without the use of flux adjustments, though a very small drift remains in the deep ocean (Pardaens et al. 2003). Convection in HadCM3 is parametrised by the Rahmstorf (1993) scheme, and the overflow over the GIS ridge is modified by using the Roussenov convection scheme (Roether et al. 1994). These parametrisations lead to overflows over the GSR that are reasonable for a model of limited resolution (Wood et al. 1999; Thorpe et al. 2004), with deep water formed in the Labrador and in the GIN seas (Wood et al. 1999).

Our initial interest was in the climatic response to a moderate weakening of the Atlantic MOC, rather than an abrupt collapse of the circulation. In the sensitivity experiments reported here, therefore, we added a constant freshwater flux of $0.1 \mathrm{~Sv}$ distributed across the various domains in the North Atlantic or Arctic Ocean basins shown in Fig. 1a.

A freshwater flux of this magnitude is rather large in the context of the present climate. Total runoff from the Amazon River is estimated to be about this magnitude (Stouffer et al. 2006), and the ice and water import into the GIN Sea through the Fram Strait is estimated to be about 3,950 $\mathrm{km}^{3} /$ year (Aagaard and Carmack 1989), corresponding to about $0.13 \mathrm{~Sv}$. In the context of a future warmer climate, though, this magnitude might be reached by the runoff from a melting Greenland ice sheet (Jungclaus et al. 2006; Driesschaert et al. 2007). In the context of past changes in climate, on the other hand, a freshwater flux of this magnitude is not unreasonable. Teller et al. (2002) estimate that $163,000 \mathrm{~km}^{3}$ may have been released from Lake Agassiz prior to the 8.2-ka event, which would correspond to a flux of $5.2 \mathrm{~Sv}$ if released during 1 year, or $0.05 \mathrm{~Sv}$ if released over the 100 years of our experiments.

We performed four experiments, releasing the freshwater in the following locations:

1. CMIP: The freshwater is added to the North Atlantic basin between latitudes $50^{\circ} \mathrm{N}$ and $70^{\circ} \mathrm{N}$, similar to the experimental setup in Stouffer et al. (2006).

2. SIB: The freshwater is added to the Arctic Ocean north of the Siberian coast.

3. LAR: The freshwater is added to the North Atlantic basin to a larger area north of the CMIP area.

4. LOC: The freshwater is added to the North Atlantic basin to a localised area covering parts of the GIN Sea and the Barents Sea.

All of these experiments are started from year 100 of a control run climate, which was itself initialised from year 2789 of the HadCM3 control run performed at the Hadley Centre (Collins et al. 2001). The initial model state from which the experiments are initialised is,
Fig. 1 a Locations of freshwater hosing in experiments CMIP (black), SIB (red), LAR (blue) and LOC (green). b Maximum of the meridional overturning streamfunction in the North Atlantic basin. Shown are 10-year Gaussian-weighted smoothed timeseries for the control run (black crosses), and experiments CMIP (black), SIB (red), LAR (blue) and LOC (green). Black dashed lines are the control run mean, as well as 30 -year mean values from the end of each hosing experiment. Thin dotted lines are plus and minus two standard deviations of control run MOC
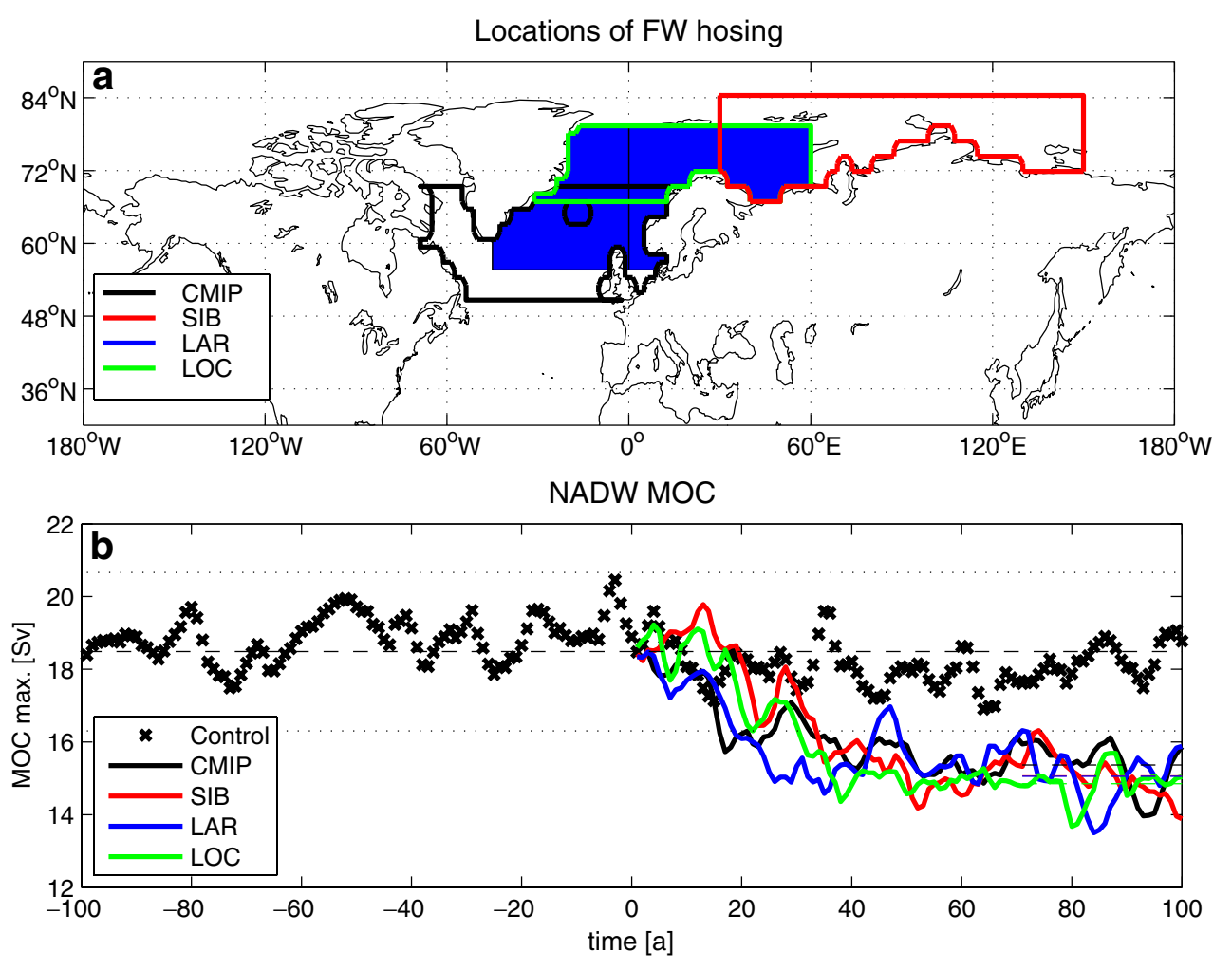
therefore, relatively stable. In the perturbation experiments, freshwater is added at a constant rate of $0.1 \mathrm{~Sv}$ until the end of the experiment. The first year of the freshwater experiments is labelled as year 1 throughout this paper. The mean climatic response in years 71-100 of the experiments is compared to the control run state. Where appropriate, statistical significance of the difference between experiment and control is tested by performing a $t$ test against the six available nonoverlapping 30-year sections of control run climate. For the analysis of the physical reasons for the warming in the GIN Sea in Section 4, we concentrate on the control run and experiment CMIP.

\section{Results}

As a measure of MOC strength, a timeseries of the maximum of the annual mean meridional overturning streamfunction in the experiments is shown in Fig. 1b. Shown are the MOC timeseries after smoothing with a 10-year Gaussian-weighted filter. The control run, shown as a thick black dotted line, has a mean overturning of $18.5 \mathrm{~Sv}$. In the freshwater hosing experiments, the circulation starts to decrease quickly, and the mean overturning strength in years $71-100$ is $15.4 \mathrm{~Sv}$ for CMIP, 15.1 Sv for Sib, 15.1 Sv for LAR and 14.9 Sv for LOC.

These reductions in overturning are basically as one would expect. The decline in MOC strength happens more quickly if the freshwater is added close to the deep water formation region. It takes some time for the freshwater to be advected to the deep water formation region if the hosing takes place further away, as is apparent in experiment SIB, where the freshwater is added to the Arctic Ocean.

What one would also expect to see in experiments similar to the ones performed here is that a reduction in MOC would lead to a reduction in meridional heat transport, which would in turn lead to a general cooling in the North Atlantic area. Stouffer et al. (2006) showed that this is actually not the case in some of the climate models they investigated. Rather, they found warming
Fig. 2 Change in 30-year mean DJF SAT over land or SST over sea for experiments CMIP, SIB, LAR and LOC, relative to control. White areas: changes not significant at a significance level of 0.05

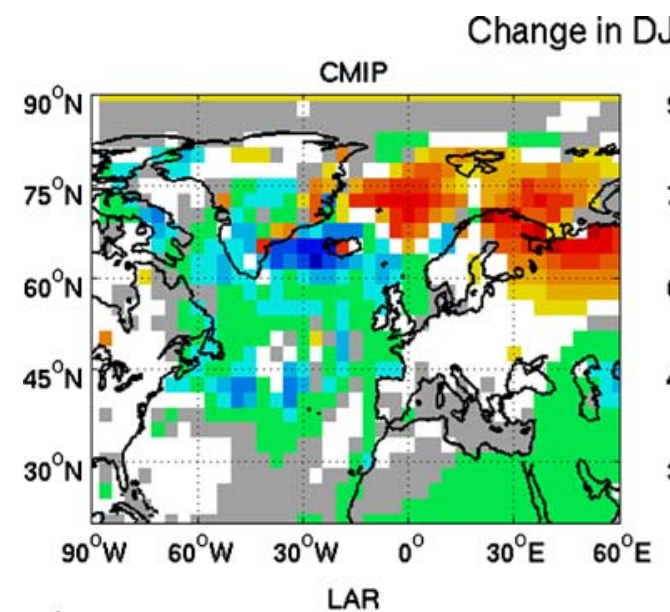

\section{Change in DJF temperature}
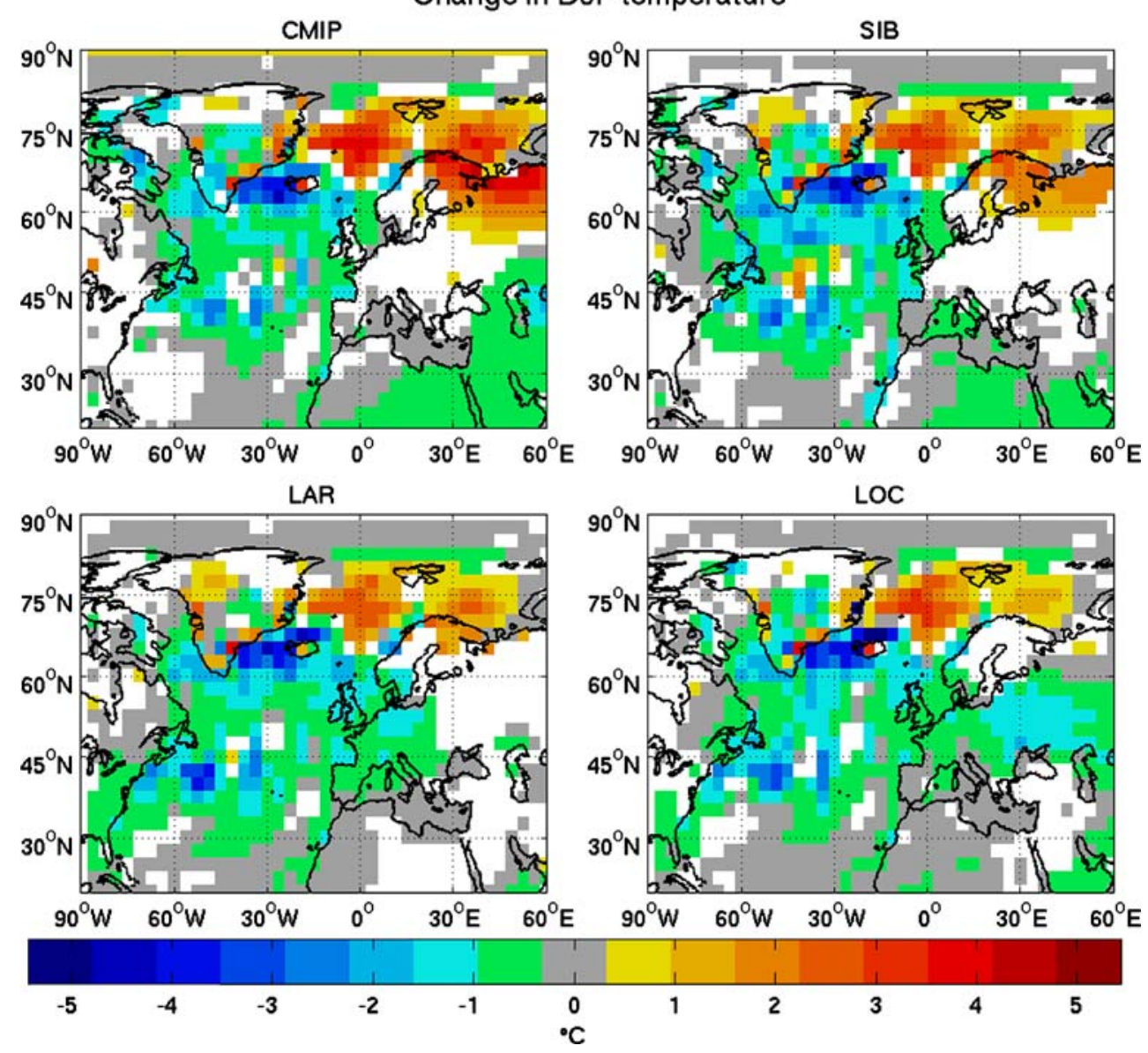
in some areas of the North Atlantic basin, particularly the Barents Sea, in five general circulation models including the HadCM3 model being used here, which was the main motivation for the present study.

Figure 2 shows the change in winter surface air temperature (SAT) over land, and sea surface temperature (SST) over the ocean areas in the four model experiments. It is quite obvious that there is a significant warming in the GIN Sea at about $70^{\circ} \mathrm{N}$ in all four of the experiments, which extends eastwards into the Barents Sea. The SST warms by up to $4^{\circ} \mathrm{C}$ in the GIN Sea in experiment CMIP, with slightly less warming in the three other experiments. SAT over eastern Scandinavia also increases significantly in all experiments except LOC, with SAT change strongest in CMIP and weakest in LAR.

In these freshwater hosing experiments, convection depth, indicated in Fig. 3 by the mixed layer depth, increases in the GIN Sea area. The change in convection leads to the increase in SST due to warmer subsurface waters being mixed with rather cold surface waters. If one were to consider experiment CMIP only, one could speculate that the change in convection was due to a shift in the location of convection from the area where freshwater hosing is applied to just north of this area. However, our multiple experiments show that this clearly does not explain the phenomenon, since a very similar change in convection depth takes place in the other three experiments, despite the very different locations of freshwater hosing. In experiment SIB, no freshwater is added in the band $50^{\circ}-70^{\circ} \mathrm{N}$ at all. Therefore, the observed shift in convection cannot be due to the direct suppression of convection due to the localised addition of surface freshwater. In experiment LAR, on the other hand, the freshwater is added both in the area that shows a reduction in convection and in the area that shows an increase in convection, but the change in convection is rather similar to experiment CMIP. Finally, in experiment LOC, the freshwater is added in a rather narrow band centred on those places where the increase in convection depth takes place in experiments CMIP and LAR. Despite the concentrated addition of freshwater in this area, the change in convection is still very similar to the three other cases.
Fig. 3 Change in 30-year mean DJF mixed layer depth in experiments CMIP, SIB, LAR and LOC, relative to control. Values range from -260 to $+263 \mathrm{~m}$

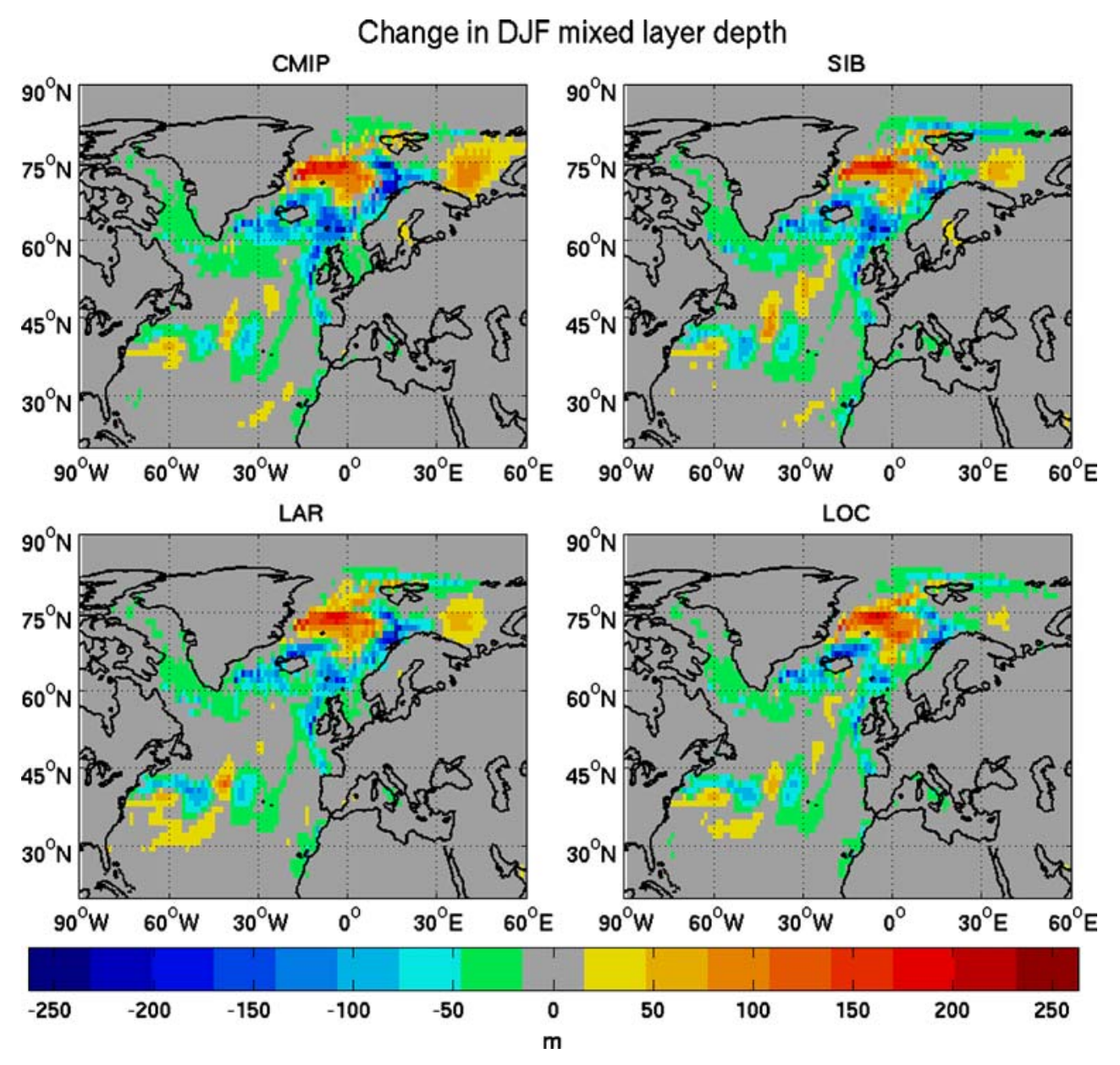


Finally, annual mean sea surface salinity (SSS) shows very similar changes in all four experiments across the Atlantic Ocean (Fig. 4), though some differences are apparent in the Barents Sea and the Arctic Ocean. In all experiments, SSS increases by up to 2 psu east of Greenland between $70^{\circ} \mathrm{N}$ and $75^{\circ} \mathrm{N}$, while SSS generally decreases south of this area. In the eastern Barents Sea, SSS increases strongly in experiment CMIP, while the increase is less strong in experiment LAR. In experiment SIB, there is only a very weak increase (and reduced salinity further east), while there is a decrease in SSS in experiment LOC.

In the following section, we will focus on experiment CMIP to investigate the reasons for the increased vertical mixing, temperature and salinity in parts of the far North Atlantic in these HadCM3 model simulations. The strong increase in the surface salinity of the northwestern GIN Sea, directly where the anomalous surface fluxes are concentrated in the LOC experiment that would be expected to induce surface freshening, indicates that a rather complex dynamical response takes place.

\section{Physical reasons for warming in the GIN Sea}

\subsection{Diagnosed changes in the experiments}

Annual mean SST in the North Atlantic area for the control run climate is shown on the left side of Fig. 5. Temperatures above $15^{\circ} \mathrm{C}$ are limited to latitudes south of $45^{\circ} \mathrm{N}$. The coldest temperatures of about $0^{\circ} \mathrm{C}$ occur in the Arctic, around northern Greenland, and in the Barents Sea. The majority of the GIN Sea is rather cool at about $5^{\circ} \mathrm{C}$, and it is only south of $70^{\circ} \mathrm{N}$, as well as along the Norwegian coast, that temperatures rise above this mark. The area east of Iceland has a temperature of about $10^{\circ} \mathrm{C}$.

The distribution of surface salinity, shown on the right side of Fig. 5, is quite different from the
Fig. 4 Change in 30-year mean surface salinity in experiments CMIP, SIB, LAR and LOC, relative to control

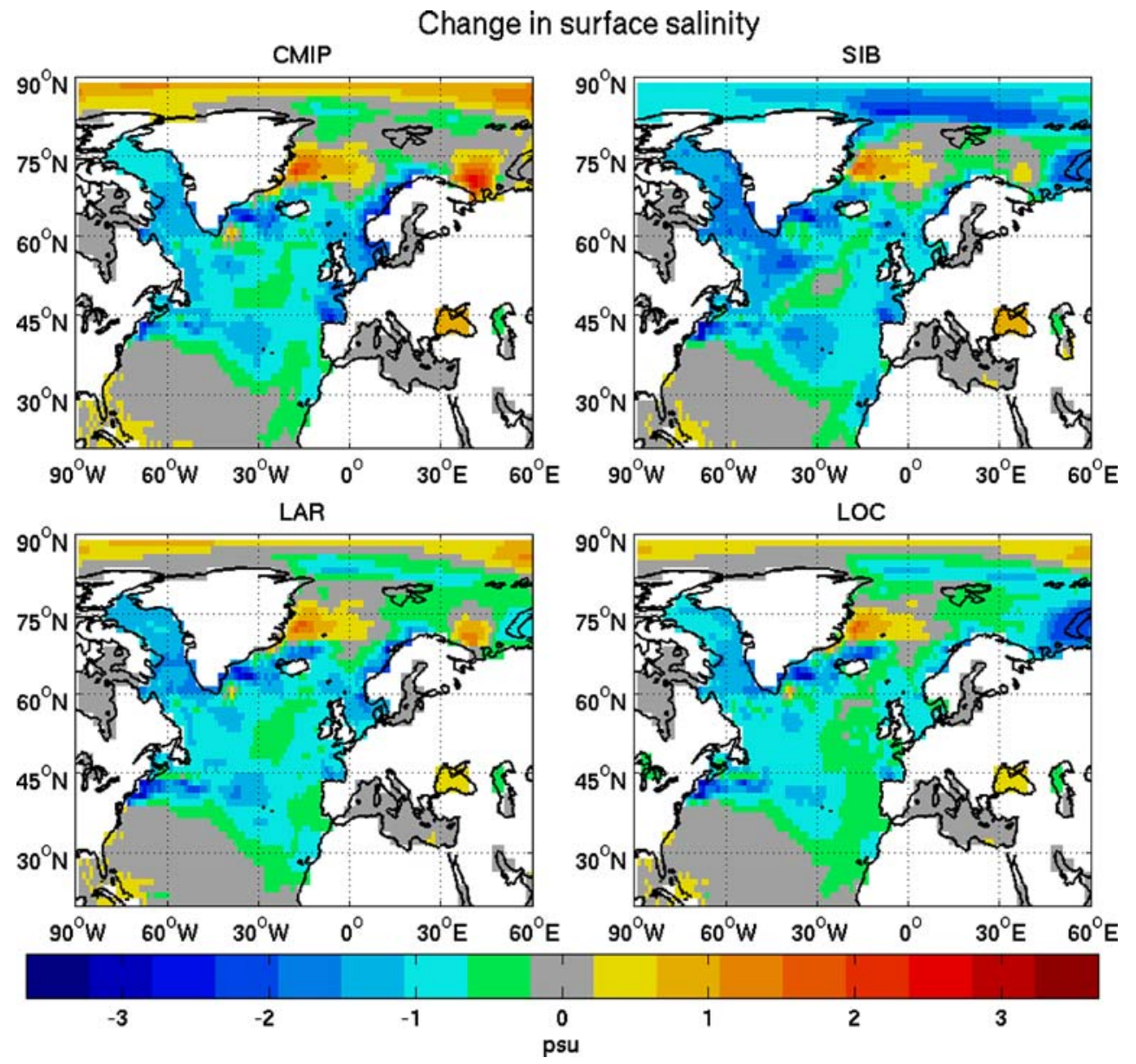



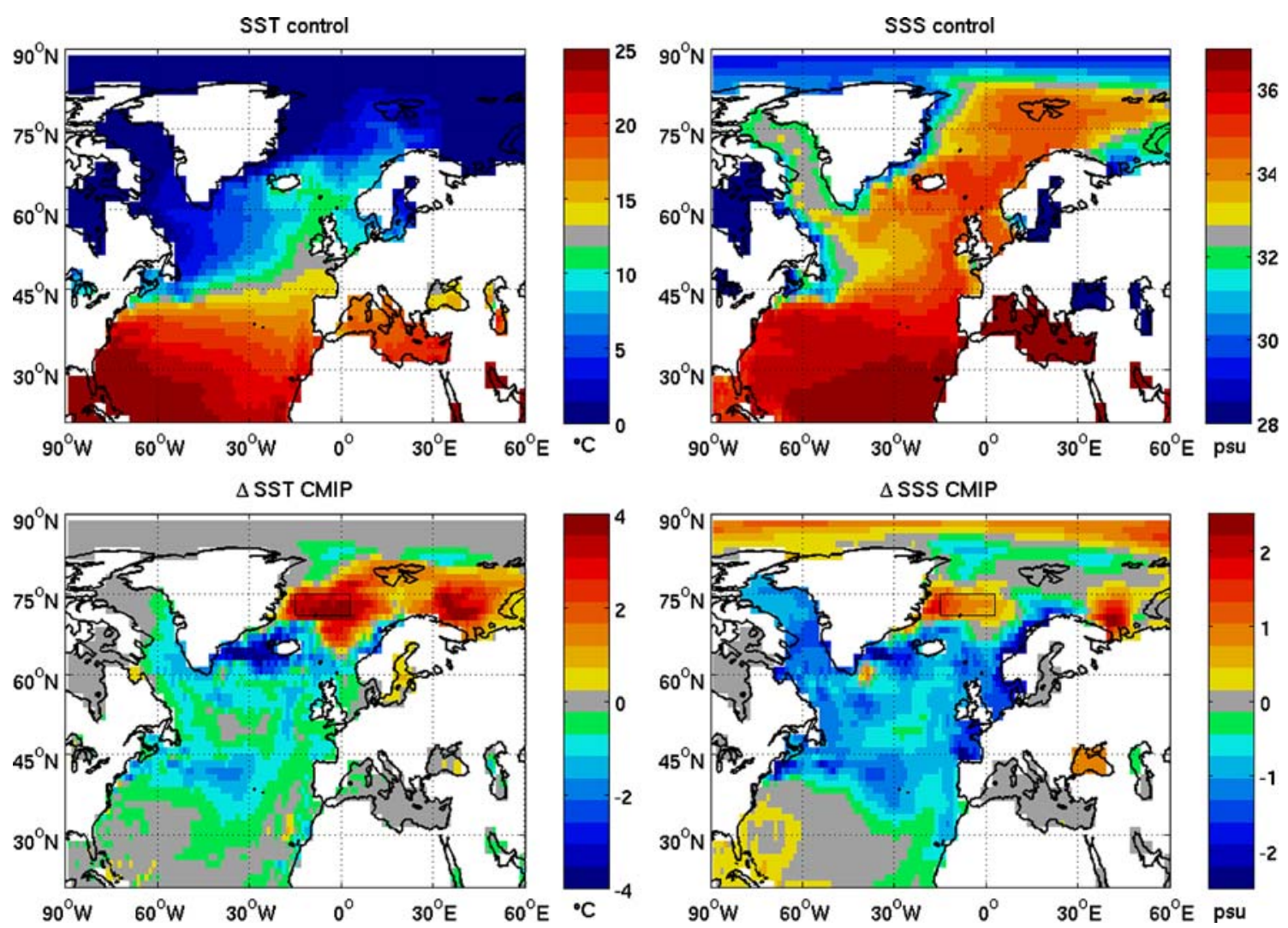

Fig. 5 Sea surface temperature (SST, left) $\left({ }^{\circ} \mathrm{C}\right)$ and salinity $(S S S$, right) (psu) in the control run (upper half) and change in experiment CMIP (lower half). The black boxes in the lower panels indicate the region of maximum warming investigated in more detail

temperature distribution. Salinities below 33 psu occur in the Arctic, in the East Greenland Current, as well as in the Labrador and southern Barents seas. Apart from the East Greenland Current, salinity in the GIN Sea is generally at about 34 psu or higher.

In the control run, convection (not shown) intermittently reaches depths of 1,400-2,000 $\mathrm{m}$ in the Labrador Sea, and about 1,200 $\mathrm{m}$ in the Irminger and GIN seas. The GIN Sea is the area where convection is most widespread, and occurs every winter, while Labrador Sea convection is limited to a few grid points and only in some winters.

In measurement data from surface drifters (Reverdin et al. 2003; Flatau et al. 2003), the subpolar gyre consists of two distinct parts. The western part involves the Irminger Current flowing northward along the western flank of the Reykjanes Ridge, which then connects to the East Greenland, West Greenland, and Labrador currents. There also is an eastern part, consisting of northward flow through the Rockall Trough or the Maury Channel, and westward flow south of Iceland. Surface drifter data show only a very weak connection between these parts, with some southwestward flow along the eastern flank of Reykjanes Ridge. Inverse estimates, on the other hand, show substantial transport across Reykjanes Ridge (Bacon 1997). In an intercomparison of eddy-resolving ocean models, Treguier et al. (2005) show these parts to be connected, with a strong current along the eastern flank connecting the two parts of the sub-polar gyre, as well as some flow across the ridge. These authors also mention that differences between models are larger than interannual variability within a single model.

In comparatively low-resolution models like HadCM3, the sub-polar gyre consists of one continuous circulation cell, branching off from the North Atlantic current south of Iceland and joining the East Greenland, West Greenland, and Labrador currents west of Iceland, as shown in Fig. 6.

Near-surface current speeds are about an order of magnitude smaller than in the eddy-resolving models compared in Treguier et al. (2005). In an investigation of the influence of ocean resolution on the ocean circulation, Spence et al. (2008) find that current speeds 


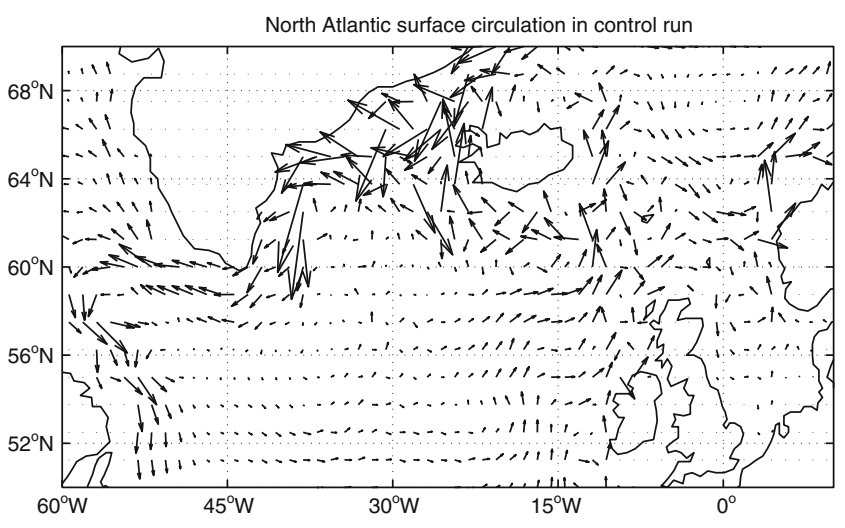

Fig. 6 Surface (0-30-m depth) circulation in the control run

increase with finer resolutions, but these authors do not report that the overall shape of the sub-polar gyre mentioned is resolution-dependent. Since Spence et al. (2008) did not change bathymetry between experiments with different resolutions, it can be speculated that the different structure of the sub-polar gyre in HadCM3 (and other low-resolution models) and eddy-resolving models is an effect of bottom topography.

The freshwater hosing experiment we report here leads to a strong change in the distributions of temperature and salinity, as shown in the lower part of Fig. 5. For ease of comparison, we show only the surface layer, but very similar changes occur in all near-surface layers. While SST and SSS decrease south of Iceland, there is a strong increase in SSS in the centre of the GIN Sea, as well as further east in the Barents Sea. In these locations, as well as in the connecting areas, there is a strong increase in SST of up to $4^{\circ} \mathrm{C}$. In addition, winter mixed layer depth increases by several hundred metres in these locations (Fig. 3). As an indicator of convection depth, it was expected that the mixed layer depth would decrease due to the stabilising influence of the freshwater forcing. Decreases are simulated, but only in the southern and eastern parts of the GIN Sea, as well as south of Iceland.

To understand the reasons for this anomalous warming, we looked at the location of maximum warming, indicated by a rectangle in the lower part of Fig. 5, in more detail. Time series of the annual mean surface density, salinity and temperature in this area, as well as the winter mixed-layer depth, are shown in Fig. 7 for control (blue) and CMIP (red). In this region, the results are very similar to each other for the first 40 years of the experiments. After year 40, winter convection depth increases strongly to about $250 \mathrm{~m}$, due to the increase in surface density, which is, in turn, due to an increase in surface salinity. SST also increases after
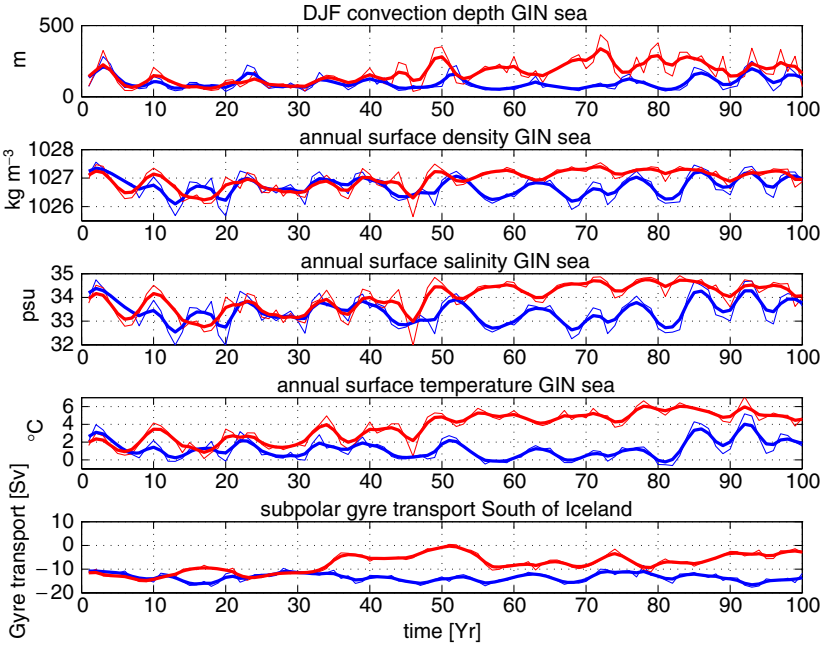

Fig. 7 DJF mixed layer depth, annual mean density, salinity and temperature in the surface layer of the area of maximum warming (indicated by the boxes in the lower panels of Fig. 5). In addition, westerly transport in the sub-polar gyre south of Iceland is shown. Thin lines are annual values, thick lines are smoothed with a 10-year filter. The control run is shown in blue and the CMIP experiment in red

year 40 , but the increase in salinity dominates the temperature increase in terms of the water density.

\subsection{Causes for temperature increase}

Gamiz-Fortis and Sutton (2007) report temperature fluctuations in the GIN Sea in the control run of HadCM3, with a quasi-periodic oscillation with a period of about 7 years. Their analysis indicates a cycling
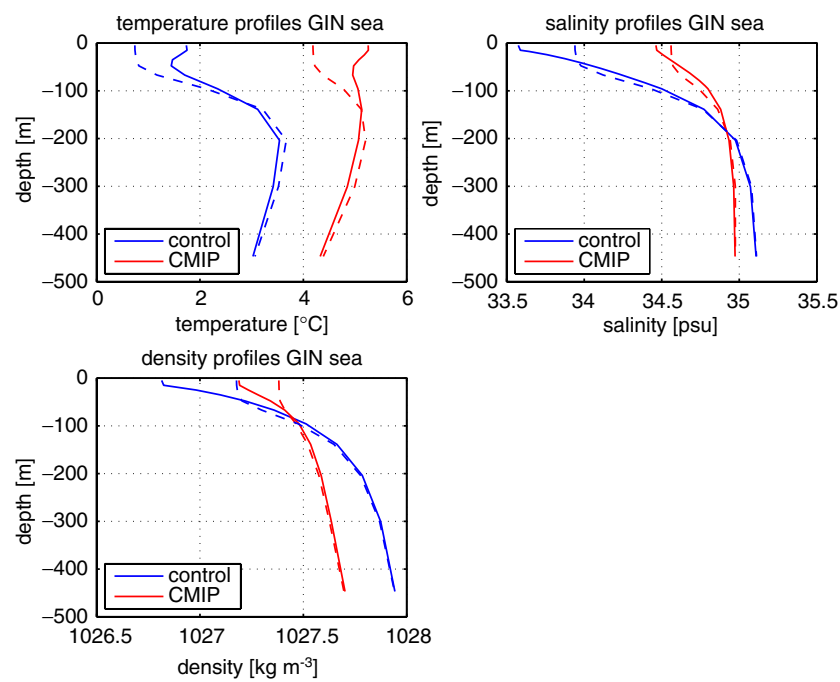

Fig. 8 Depth profiles of temperature, salinity and density for the study area for control (blue) and CMIP (red). Annual mean is shown as a solid line, DJF as a dashed line 
between states with shallower or deeper convection in this region. When convection is increased, heat is transported from the warm sub-surface waters into the upper layers, causing a strong warming at the surface. In the periods with shallower mixing, the upper layers cool.

In our experiments, this mechanism is not sufficient to explain the simulated changes. Depth profiles of potential temperature, salinity and potential density (Fig. 8) clearly show that, relative to the control run, CMIP temperature increases at all depths, while salinity and density increase at the surface and decrease at depth, leading to a much smaller gradient in salinity and density with depth. The latter is a clear signature of enhanced convection in this area. The fact that annual mean temperature at the surface becomes higher than temperature at depth excludes enhanced convection as the sole source of the temperature increase at the surface. Winter convection certainly plays a role by equalising temperatures along the water column, but it cannot explain the overall increase in temperature throughout the whole water column.

Possible explanations for the changes in surface properties in the study area are changes in surface fluxes on the one hand and changes in advection on the other hand. A decrease in precipitation, which would lead to an increase in salinity in the study area, did not occur in this region during the CMIP experiment. Warming-induced sea-ice retreat in this area actually enhances the loss of heat from the sea surface to the atmosphere. In addition, changes in sea ice (not shown), as well as changes in wind stress curl (also not shown), which could be another factor, only develop after the warming sets in. They seem to be a reaction to the surface warming, not a cause of it.

Surface fluxes, therefore, seem to be a rather unlikely cause for the simulated changes. Although the main increase in SSS (Fig. 5, bottom right) occurs north of the region of additional freshwater input in the CMIP experiment $\left(50-70^{\circ} \mathrm{N}\right)$, a similar increase occurs even when the freshwater is added to the northern GIN Sea in experiment LOC. The fact that SSS actually increases in response to additional freshwater indicates a strong dynamical ocean response. In addition, the timeseries plots in Fig. 7 show that SST and SSS vary in-phase, which points towards advection of warm saline waters as the cause of the changes in the study area.

\subsection{Gyre circulation}

Further investigation of the simulated currents into the GIN Sea area shows that there is an increase in northward velocity east of Iceland (not shown), which would enhance advective transport into the GIN Sea basin, despite the fact that overall overturning decreased. Surface wind stress fields (not shown) show incoherent changes, which implies that this change in currents is not due to wind stress forcing.

Instead, the change in transport into the GIN Sea is related to changes in the sub-polar gyre circulation south of Iceland. Figure 7, bottom, shows the depthintegrated transport in the sub-polar gyre south of Iceland. Transport is in a westward direction and, therefore, negative. While circulation in the control run, shown in blue, stays constant, the circulation changes strongly in experiment CMIP, shown in red. Here, the sub-polar gyre transport decreases by about two thirds. Häkkinen and Rhines (2004), as well as Hátún et al. (2005), have shown that reductions in sub-polar gyre circulation lead to an increase in transport into the Nordic Seas, which is clearly also the case in our model experiments. As shown by Levermann and Born (2007), a decrease of sub-polar gyre transport can be induced by small changes in the surface freshwater budget. This leads to the conclusion that the addition of freshwater in our hosing experiments causes a decrease in the sub-polar gyre circulation, which increases transport into the GIN Sea.

In addition, the vertical structure of temperature and salinity, and therefore density, in the North Atlantic changes through the addition of freshwater. Figure 9 shows the change in zonally averaged salinity and temperature in the Atlantic basin. The surface layers between about $40^{\circ} \mathrm{N}$ and $65^{\circ} \mathrm{N}$ show a strong decrease

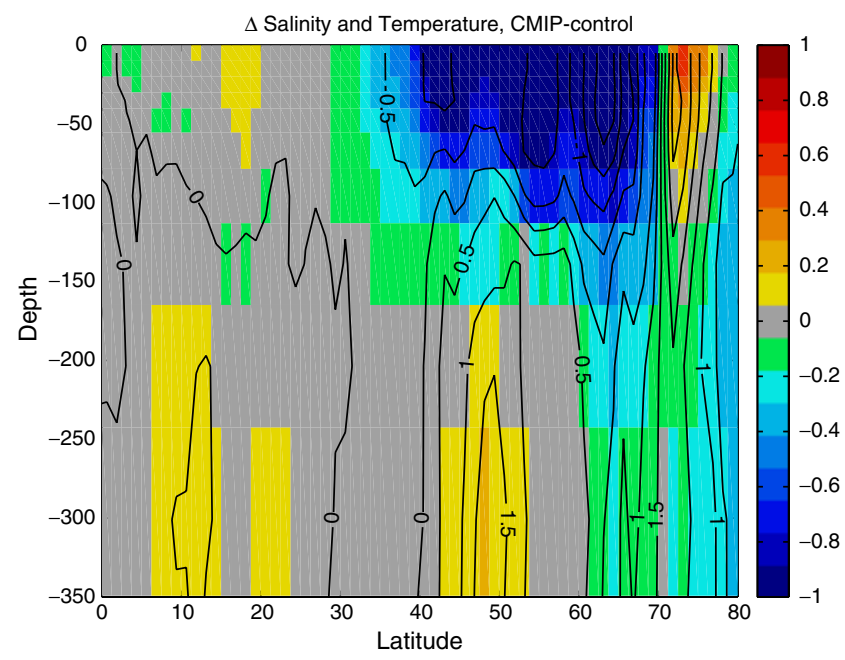

Fig. 9 Change (CMIP-control) in vertical salinity (colours) and temperature (contours) with depth and latitude in the North Atlantic basin. Salinity in psu, temperature in ${ }^{\circ} \mathrm{C}$ 
in salinity and temperature. Below this layer, salinity changes only slightly, while temperature increases by up to $1.5^{\circ} \mathrm{C}$. The surface layer is rather light, while the lower layers are more dense. A similar change in vertical structure was also observed by Mignot et al. (2007), where a low-density layer formed above the higherdensity layers as a response to freshwater hosing.

This warmer sub-surface water is then transported below the surface into the GIN Sea basin by the currents that are enhanced by the change in sub-polar gyre transport. Quantifying this, the volume transport across $65^{\circ} \mathrm{N}$ between Iceland and Norway in the upper $530 \mathrm{~m}$ increases from 8.1 to $10.9 \mathrm{~Sv}$. In the control run, the water flowing through the upper $110 \mathrm{~m}$ of this cross section has an average salinity of $35.0 \mathrm{psu}$, and a mean potential temperature of $8.8^{\circ} \mathrm{C}$, while the water between 110 and 530-m depth has values of $35.3 \mathrm{psu}$ and $8.1^{\circ} \mathrm{C}$. In the CMIP experiment, these values change to a mean salinity of $33.8 \mathrm{psu}$ and temperature of $8.1^{\circ} \mathrm{C}$ in the upper $110 \mathrm{~m}$, and to $35.1 \mathrm{psu}$ and $9.7^{\circ} \mathrm{C}$ between 110 and $530 \mathrm{~m}$. Clearly, the surface layer gets colder and fresher, while the water below the surface warms, with salinity staying more or less constant.

Therefore, the simulated warming in the GIN Sea is due to the following chain of events: Initially, the addition of freshwater leads to a surface freshening and cooling, while the lower layers are warmed by the suppression of vertical mixing in the GIN Sea and the region south of Iceland. The sub-polar gyre circulation reduces due to the addition of freshwater, which leads to enhanced mass transport into the GIN Sea. The enhanced mass transport and the sub-surface warming result in increased sub-surface heat transport into the GIN Sea. Here, below-surface conditions change: temperature increases while there is a small decrease in salinity. Below-surface density therefore decreases throughout the GIN Sea basin, facilitating winter convection. Once convection sets in, the warm water is mixed throughout the water column, leading to a strong increase in surface temperature and salinity.

\section{Summary and discussion}

In this paper, we have investigated the climate system response to freshwater hosing in different highlatitude locations. To this end, we have performed four experiments with $\mathrm{HadCM} 3$, where we have added an additional $0.1 \mathrm{~Sv}$ of freshwater, sustained for 100 years, to: (1) the North Atlantic between 50 and $70^{\circ} \mathrm{N}$ (experiment CMIP), (2) the Arctic Ocean north of the Siberian Coast (SIB), (3) to the North Atlantic basin to a larger area north of the CMIP area (LAR), and (4) to a localised area of the North Atlantic basin covering parts of the GIN Sea and the Barents Sea (LOC).

In all four experiments, the MOC decreases by roughly $25 \%$ compared to the control run. Despite this decrease in overturning, which implies a decrease in meridional heat flux, the HadCM3 response is a warming in the high-latitude North Atlantic, while temperatures south of Iceland decrease. The warming can reach up to $4^{\circ} \mathrm{C}$ in the GIN and Barents seas, and extends eastwards into Scandinavia. In addition to the warming, the climate response consists of an increase in mixed-layer depth in those locations where warming is largest, and an increase in salinity, despite the overall freshening of the North Atlantic induced by the artificial freshwater flux.

This HadCM3 climate response is robust against variations in freshwater forcing location, appearing (with varying amplitude) in all of our freshwater hosing experiments, even if the freshwater is added in a narrow band centred on the locations of increased mixed layer depth in experiment LOC. The simulated changes cannot, therefore, be explained by small shifts in convection sites to the north of the area where freshwater is added, as one could hypothesise if confronted solely with the results of experiment CMIP.

Instead, the ocean responds dynamically to the addition of freshwater. We identified two mechanisms that are relevant here. First, surface advection of warm and comparatively saline surface water from the low latitudes into the GIN Sea is reduced and is instead overlain by a layer of cold and fresh surface water, leading to a decrease of surface temperature and salinity north of $40^{\circ} \mathrm{N}$, while there is an increase in temperature at depth. Second, the strength of the sub-polar gyre strongly decreases due to the addition of freshwater at the surface. This decrease in gyre transport leads to an increase of mass and sub-surface heat transport into the GIN Sea, where sub-surface temperature increases, and salinity does not decrease as strongly as at the surface. This decrease in sub-surface density leads to an increase in convection between $70^{\circ} \mathrm{N}$ and $75^{\circ} \mathrm{N}$, which leads to the strong warming at the sea surface that motivated this investigation.

The experiments were conducted with an idealised experimental setup, and several changes could be made to make these experiments more "realistic". One of the simplifications of HadCM3 is that the Bering Strait is closed in the model. Usually, it is assumed that this does not affect the circulation in a major way (Pardaens et al. 2003), but there is a transport of about $0.8 \mathrm{~Sv}$ of relatively fresh Pacific water through the Bering Strait (Aagaard and Carmack 1989). In the case of experiment SIB, where freshwater is added to the 
Arctic Ocean off the Siberian coast, this might have an influence. We can only speculate about the likely influence of the open/closed strait here since we did not have such a model configuration available. Transport through the Bering Strait seems to be controlled by the dynamic sea level differences between the Pacific and the Arctic (Shaffer and Bendtsen 1994; Hu et al. 2007). An addition of freshwater into the Arctic Ocean would lead to a decrease in density there, which in turn would lead to a rise in sea level, thereby reducing the inflow from the Pacific Ocean. The magnitudes of this effect are impossible to quantify without model experiments, but this could lead to a reduction of the overall effect on the MOC, if freshwater is added to the Arctic Ocean.

Another idealisation in our experiments is the fact that we added the freshwater to broad areas of ocean instead of allowing the model to transport it to the deep water formation areas by boundary currents. We performed two sensitivity experiments (not shown) to determine whether this would make a qualitative difference to the model results we report. In one experiment, we increased Greenland runoff, thereby adding the freshwater to the East and West Greenland currents, and in another experiment, we added the freshwater to the Caribbean area, thereby decreasing salinity in the Gulf Stream. In both experiments, results were qualitatively similar to the experiments described here, with the warming in the GIN sea quite prominent, but quantitatively, the effect on the MOC was weaker, since some of the additional freshwater is recirculated in the sub-tropical gyre and does not reach the deep-water formation areas.

The results reported in this publication may be quite dependent on the model used to investigate these questions. Stouffer et al. (2006) report a similar warming for four of the 14 models taking part in the intercomparison (including HadCM3). Therefore, the mechanism reported here may be relevant for some other climate models as well. The parametrisation of convection may have a strong influence on our results, as could the horizontal resolution, especially if it were sufficiently fine to resolve eddies.

Some aspects of this mechanism have been identified before, however, both from ocean models at a range of resolutions and from measurement data. Häkkinen and Rhines (2004) report measured changes in sea surface height and reductions in sub-polar gyre circulation during the 1990s. They performed model experiments and linked the reductions in sub-polar gyre strength to changes in local buoyancy forcing. Hátún et al. (2005) investigated the influence of sub-polar gyre strength on the inflow into the GIN sea, combining a model of $20-\mathrm{km}$ resolution and measurement data. They conclude that the strength of the sub-polar gyre has a major influence on salinity in the GIN sea, with strong gyre circulation leading to a reduction in inflow into the GIN sea, and vice versa. Böning et al. (2006) confirmed their results using models of $1 / 3^{\circ}$ and $1 / 12^{\circ}$ resolution. Changes in sub-polar gyre leading to changes in inflow into the GIN sea seem, therefore, to be quite robust and independent of model resolution.

The other parts of the mechanism reported here, an increase in sub-surface salinity and temperature due to capping by the added freshwater, as well as the cause of the changes in sub-polar gyre strength, which we attribute to changes in density structure seem, for now at least, to be model-dependent. While it appears very plausible that capping by freshwater leads to a subduction of warm and salty sub-tropical water under the layer of fresh and cold water that is formed in the region of freshwater hosing, as shown by Mignot et al. (2007) using the Climber-3 $\alpha$ model, this may be limited to a few models, and possibly also to models of comparatively low resolution. Similarly, it is quite clear that sub-polar gyre strength is dependent on both wind stress forcing and on density structure in the sub-polar North Atlantic (Eden and Willebrand 2001; Böning et al. 2006), with Labrador Sea convection and density of overflow waters both having an impact on sub-polar gyre strength. Finally, Levermann and Born (2007) have shown that the addition of freshwater at the surface can change sub-polar gyre strength. This mechanism, therefore, also appears to be physically plausible and quite robust across models.

All elements of the physical mechanism leading to warming in the GIN sea appear to be physically plausible, therefore, and not restricted to HadCM3. Nonetheless, the mechanism described here is potentially very model-dependent. The parametrisations of vertical mixing processes, i.e. mixed-layer parametrisations, convection parametrisation and overflow parametrisation, may have a major influence on model reaction to the addition of freshwater. Similarly, change to a higher (eddy-resolving) resolution may lead to changes in model behaviour. Unfortunately, the effect of all these factors is impossible to evaluate without running appropriate model experiments.

It remains unclear, therefore, whether this behaviour is limited to a few coupled general circulation models such as HadCM3, or whether such localised warming might occur in the real climate system following a partial weakening of the Atlantic MOC. Further detailed analysis of model-simulated processes and comparison with observations of real ocean response under varying surface forcing is required. 
Acknowledgements This study was supported by the UK Natural Environment Research Council Rapid Climate Change Programme, grant no. NE/C509507/1. We are grateful to Mat Collins for advice concerning the HadCM3 experiments and for access to the UEA e-science cluster on which the model integrations were performed. We would also like to thank Anders Levermann, Gerard van der Schrier, Eva Bauer and Michael Vellinga for stimulating discussions. Finally, we would like to thank two anonymous reviewers for their helpful suggestions for improving the manuscript.

\section{References}

Aagaard K, Carmack EC (1989) The role of sea ice and other fresh water in the Arctic circulation. J Geophys Res 94(C10):14485-14498

Bacon S (1997) Circulation and fluxes in the North Atlantic between Greenland and Ireland. J Phys Oceanogr 27:1420 1435

Böning CW, Scheinert M, Dengg J, Biastoch A, Funk A (2006) Decadal variability of subpolar gyre transport and its reverberation in the North Atlantic overturning. Geophys Res Lett 33:L21S01

Challenor PG, Hankin RKS, Marsh R (2006) Towards the probability of rapid climate change. In: Schellnhuber HJ, Cramer W, Nakicenovic N, Wigley T, Yohe G (eds) Avoiding dangerous climate change. Cambridge University Press, Cambridge, pp 55-63

Collins M, Tett SFB, Cooper C (2001) The internal climate variability of HadCM3, a version of the Hadley Centre coupled model without flux adjustments. Clim Dyn 17(1):61-81

Cuny J, Rhines PB, Schott F, Lazier J (2005) Convection above the Labrador continental slope. J Phys Oceanogr 35(4): 489-511

Driesschaert E, Fichefet T, Goosse H, Huybrechts P, Janssens I, Mouchet A, Munhoven G, Brovkin V, Weber SL (2007) Modeling the influence of Greenland ice sheet melting on the Atlantic meridional overturning circulation during the next millennia. Geophys Res Lett 34:L10707

Eden C, Willebrand J (2001) Mechanism of interannual to decadal variability of the North Atlantic circulation. J Climate 14(10):2266-2280

Fichefet T, Poncin C, Goosse H, Huybrechts P, Janssens I, Treut HL (2003) Implications of changes in freshwater flux from the Greenland ice sheet for the climate of the 21st century. Geophys Res Lett 30(17):1911

Flatau MK, Talley L, Niiler PP (2003) The North Atlantic Oscillation, surface current velocities, SST changes in the subpolar north atlantic. J Climate 16(14):2355-2369

Gamiz-Fortis SR, Sutton RT (2007) Quasi-periodic fluctuations in the Greenland-Iceland-Norwegian seas region in a coupled climate model. Ocean Dyn 57(6):541-557

Ganachaud A, Wunsch C (2000) Improved estimates of global ocean circulation, heat transport and mixing from hydrographic data. Nature 408:453-457

Gordon C, Cooper C, Senior CA, Banks H, Gregory JM, Johns TC, Mitchell JFB, Wood RA (2000) The simulation of SST, sea ice extents and ocean heat transports in a version of the Hadley Centre coupled model without flux adjustments. Clim Dyn 16(2-3):147-168

Gregory JM, Dixon KW, Stouffer RJ, Weaver AJ, Driesschaert E, Eby M, Fichefet T, Hasumi H, Hu A, Jungclaus JH,
Kamenkovich IV, Levermann A, Montoya M, Murakami S, Nawrath S, Oka A, Sokolov AP, Thorpe RB (2005) A model intercomparison of changes in the Atlantic thermohaline circulation in response to increasing atmospheric $\mathrm{CO}_{2}$ concentration. Geophys Res Lett 32:L12703

Häkkinen S, Rhines PB (2004) Decline of subpolar North Atlantic circulation during the 1990s. Science 304(5670): $555-559$

Hansen B, Østerhus S (2000) North Atlantic-Nordic Seas exchanges. Prog Oceanogr 45(2):109-208

Hátún H, Sandø AB, Drange H, Hansen B, Valdimarsson H (2005) Influence of the Atlantic subpolar gyre on the thermohaline circulation. Science 309(5742):1841-1844

$\mathrm{Hu}$ A, Meehl GA, Han W (2007) Role of the Bering Strait in the thermohaline circulation and abrupt climate change. Geophys Res Lett 34:L05704

Jansen E, Overpeck J, Briffa K, Duplessy J-C, Joos F, Masson-Delmotte V, Olago D, Otto-Bliesner B, Peltier W, Rahmstorf S, Ramesh R, Raynaud D, Rind D, Solomina O, Villalba R, Zhang D (2007) Palaeoclimate. In: Solomon S, Qin D, Manning M, Chen Z, Marquis M, Averyt K, Tignor M, Miller H (eds) Climate change 2007: the physical science basis. Contribution of working group I to the fourth assessment report of the intergovernmental panel on climate change. Cambridge University Press, Cambridge

Jungclaus JH, Haak H, Esch M, Roeckner E, Marotzke J (2006) Will Greenland melting halt the thermohaline circulation? Geophys Res Lett 33:L17708

Lavender KL, Davis RE, Owens WB (2000) Mid-depth recirculation observed in the interior Labrador and Irminger seas by direct velocity measurements. Nature 407:66-69

Levermann A, Born A (2007) Bistability of the Atlantic subpolar gyre in a coarse-resolution climate model. Geophys Res Lett 34:L24605

Manabe S, Stouffer RJ (1988) Two stable equilibria of a coupled ocean-atmosphere model. J Climate 1:841-866

Manabe S, Stouffer RJ (1995) Simulation of abrupt climate change induced by freshwater input to the North Atlantic Ocean. Nature 378:165-167

Manabe S, Stouffer RJ (1997) Coupled ocean-atmosphere model response to freshwater input: comparison to Younger Dryas event. Paleoceanography 12(2):321-336

Mignot J, Ganopolski A, Levermann A (2007) Atlantic subsurface temperatures: Response to a shutdown of the overturning circulation and consequences for its recovery. J Climate 20:4884-4898

Mikolajewicz U, Voss, R (2000) The role of the individual airsea flux components in $\mathrm{CO}_{2}$-induced changes of the ocean's circulation and climate. Clim Dyn 16(8):627-642

Pardaens AK, Banks HT, Gregory JM, Rowntree PR (2003) Freshwater transports in HadCM3. Clim Dyn 21:177-195

Park Y-G (1999) The stability of thermohaline circulation in a two-box model. J Phys Oceanogr 29(12):3101-3110

Peltier WR, Vettoretti G, Stastna M (2006) Atlantic meridional overturning and climate response to Arctic Ocean freshening. Geophys Res Lett 33:L06713

Pope VD, Gallani ML, Rowntree PR, Stratton RA (2000) The impact of new physical parametrizations in the Hadley Centre climate model: HadAM3. Clim Dyn 16(2-3):123-146

Rahmstorf S (1993) A fast and complete convection scheme for ocean models. Ocean Model 101:9-11

Rahmstorf S (1995) Bifurcations of the Atlantic thermohaline circulation in response to changes in the hydrological cycle. Nature 378:145-149

Rahmstorf S (1996) On the freshwater forcing and transport of the Atlantic thermohaline circulation. Clim Dyn 12:799-811 
Rahmstorf S, Ganopolski A (1999) Long-term global warming scenarios computed with an efficient coupled climate model. Clim Change 43:353-367

Renssen H, Goosse H, Fichefet T, Campin JM (2001) The 8.2 kyr BP event simulated by a global atmosphere-sea-ice-ocean model. Geophys Res Lett 28(8):1567-1570

Reverdin G, Niiler PP, Valdimarsson H (2003) North Atlantic Ocean surface currents. J Geophys Res 108(C1):3002

Roether W, Roussenov VM, Well R (1994) A tracer study of the thermohaline circulation of the eastern Mediteranean. In: Ocean processes in climate dynamics: global and Mediterranean examples. Kluwer Acad., Dordrecht, pp 371-394

Rooth C (1982) Hydrology and ocean circulation. Prog Oceanogr 11:131-149

Saenko OA, Weaver AJ, Robitaille DY, Flato GM (2007) Warming of the subpolar Atlantic triggered by freshwater discharge at the continental boundary. Geophys Res Lett 34:L15604

Scott JR, Marotzke J, Stone PH (1999) Interhemispheric thermohaline circulation in a coupled box model. J Phys Oceanogr 29:351-365

Shaffer G, Bendtsen J (1994) Role of the Bering Strait in controlling North Atlantic ocean circulation and climate. Nature 367:354-357

Spence JP, Eby M, Weaver AJ (2008) The sensitivity of the Atlantic meridional overturning circulation to freshwater forcing at eddy-permitting resolutions. J Climate 21(11): 2697-2710

Stocker TF, Schmittner A (1997) Influence of $\mathrm{CO}_{2}$ emission rates on the stability of the thermohaline circulation. Nature 388:862-865

Stommel H (1961) Thermohaline convection with two stable regimes of flow. Tellus 13:224-241

Stouffer RJ, Dixon KW, Spelman MJ, Hurlin W, Yin J, Gregory JM, Weaver AJ, Eby M, Flato GM, Robitaille DY, Hasumi H, Oka A, Hu A, Jungclaus JH, Kamenkovich IV, Levermann A, Nawrath S, Montoya M, Murakami S, Peltier WR, Vettoretti G, Sokolov A, Weber SL (2006) Investigating the causes of the response of the thermohaline circulation to past and future climate changes. J Climate 19(8):1365-1387

Tarasov L, Peltier W (2005) Arctic freshwater forcing of the Younger Dryas cold reversal. Nature 435:662-665

Teller JT, Leverington DW, Mann JD (2002) Freshwater outbursts to the oceans from glacial Lake Agassiz and their role in climate change during the last deglaciation. Quat Sci Rev 21(8-9):879-887

Thorpe RB, Gregory JM, Johns TC, Wood RA, Mitchell JFB (2001) Mechanisms determining the Atlantic thermohaline circulation response to greenhouse gas forcing in a non-flux-adjusted coupled climate model. J Climate 14(14): $3102-3116$

Thorpe RB, Wood RA, Mitchell JFB (2004) Sensitivity of the modelled thermohaline circulation to the parameterisation of mixing across the Greenland-Scotland ridge. Ocean Model 7(3-4):259-268

Treguier AM, Theetten S, Chassignet EP, Penduff T, Smith R, Talley L, Beismann JO, Böning C (2005) The North Atlantic subpolar gyre in four high-resolution models. J Phys Oceanogr 35(5):757-774

Vellinga M, Wood RA (2008) Impacts of thermohaline circulation shutdown in the twenty-first century. Clim Change 91(1-2):43-63

Warren BA (1981) Deep circulation of the world ocean. In: Warren BA, Wunsch C (eds) Evolution of physical oceanography. MIT, Cambridge, pp 6-40

Wiersma AP, Renssen H (2006) Model-data comparison for the 8.2 ka BP event: confirmation of a forcing mechanism by catastrophic drainage of Laurentide Lakes. Quat Sci Rev 25(1-2):63-88

Wiersma AP, Renssen H, Goosse H, Fichefet T (2006) Evaluation of different freshwater forcing scenarios for the $8.2 \mathrm{ka}$ BP event in a coupled climate model. Clim Dyn 27(7-8): 831-849

Wood RA, Keen AB, Mitchell JFB, Gregory JM (1999) Changing spatial structure of the thermohaline circulation in response to atmospheric $\mathrm{Co}_{2}$ forcing in a climate model. Nature 399:572-575 